\title{
Correction to: CRISPR-like sequences in Helicobacter pylori and application in genotyping
}

Khotchawan Bangpanwimon', Jaksin Sottisuporn², Pimonsri Mittraparp-arthorn', Warattaya Ueaphatthanaphanich ${ }^{3}$, Attapon Rattanasupar ${ }^{4}$, Christine Pourcel ${ }^{5}$ and Varaporn Vuddhakul ${ }^{1 *}$

\section{Correction to: Gut Pathog (2017) 9:65} https://doi.org/10.1186/s13099-017-0215-8

In the original version of this article [1], published on 17 November 2017, Table 2 contains an error: the first " $\mathrm{T}$ " in the first sequence in the column 'Consensus direct repeats (CDRs) sequences' has been incorrectly underlined. In Table 2, the underlining indicates the Consensus sequence.

- The sequence was originally underlined like this: AACAGCACTTTCAATCAAGGGACTTACAA

- The sequence should have been underlined like this: AACAGCACTTTCAATCAAGGGACTTACAA

The original publication of this article has been corrected.

\section{Author details}

${ }^{1}$ Department of Microbiology, Faculty of Science, Prince of Songkla University, Hat Yai, Thailand. ${ }^{2}$ NKC Institute of Gastroenterology and Hepatology, Songklanagarind Hospital, Faculty of Medicine, Prince of Songkla University, Hat
Yai, Thailand. ${ }^{3}$ Microbiology Laboratory, Vichaiyut Hospital, Bangkok, Thailand. ${ }^{4}$ KC Center of Gastroenterology and Hepatology, Hat Yai Hospital, Hat Yai, Thailand. ${ }^{5}$ Institute for Integrative Biology of the Cell (I2BC), CEA, CNRS, Univ. Paris-Sud, Université Paris-Saclay, Gif-sur-Yvette, France.

The original article can be found online at https://doi.org/10.1186/ s13099-017-0215-8.

\section{Publisher's Note}

Springer Nature remains neutral with regard to jurisdictional claims in published maps and institutional affiliations.

Received: 18 November 2017 Accepted: 27 November 2017

\section{Reference}

1. Bangpanwimon K, Sottisuporn J, Mittraparp-arthorn P, Ueaphatthanaphanich W, Rattanasupar A, Pourcel C, Vuddhakul V. CRISPR-like sequences in Helicobacter pylori and application in genotyping. Gut Pathog. 2017;9:65. https://doi.org/10.1186/s13099-017-0215-8.

*Correspondence: varaporn.v@psu.ac.th

1 Department of Microbiology, Faculty of Science, Prince of Songkla

University, Hat Yai, Thailand

Full list of author information is available at the end of the article 